\title{
The Diencephalic Syndrome of Russell: A Case Report
}

\author{
Roka YB' ${ }^{1}$ Paudel G², KC Bidur ${ }^{3}$, Munakomi S ${ }^{4}$
}

${ }^{1}$ Yam B. Roka, M.S, M.Ch (Neurosurgery), FNNI (Skull Base Surgery), Additional Professor, ${ }^{2}$ G. Paudel, MBBS, Senior Resident Surgery, ${ }^{3}$ Bidur K.C., MBBS, Resident Surgery, ${ }^{4}$ S. Munakomi, MBBS, Surgery Resident. All from the Neurosurgical Unit, Department of Surgery, B.P. Koirala Institute of Health Sciences, Dharan, Nepal.

Address for Correspondence: Dr. Yam. B. Roka, E-mail: dryamroka@yahoo.com

\begin{abstract}
Diencephalic Syndrome (DS) is also known as Russells Syndrome. This is associated with marked emaciation, locomotor hyperactivity, vomiting, and absence of obvious neurological signs and loss of subcutaneous fat. A 15-month old child who presented with hyperactivity, loss of weight and failure to thrive since bi rth is reported. On Computed Tomography he had a large supra sellar mass with extension into the third ventricle causing gross hydrocephalus. He underwent biventricular shunting followed by microscopic near total excision of the tumor. The histopathology revealed it to be fibrillary meningioma. Although DS is uncommon it must be kept as a differential diagnosis in all children who fail to grow despite adequate intake.
\end{abstract}

Key words: Childhood tumors, glioma, hydrocephalus, russells syndrome, suprasellar mass,

\section{Introduction}

$D^{\prime}$ encephalic syndrome (DS) which is also known as Russell syndrome was first described in $1951^{1}$. This syndrome consisted of hyperkinesis, increased motor activity, loss of subcutaneous fat and marked emaciation with normal food intake. This disorder affects the age groups from early infancy to childhood (mean age of onset $=6.2$ months) with $60 \%$ affected within first 6 months, $26 \%$ in the second 6 months and the rest within 3 years. One of the earliest series was by Addy and Hudson who reviewed and summarized 48 similar cases in $1972^{2}$.

Details of DS were described by Burr et al., who reported five of their own cases and summarized 67 from the literature ${ }^{3}$. Their diagnosis was done on the basis of skull and optic foramina plain Skiagrams, pneumoencephalography and final confirmation with surgery. DS is usually associated with sellar, hypothalamic, optic chiasmal, third ventricular and even posterior fossa tumors ${ }^{4,5,6}$. Due to the rarity of this syndrome the literature consists of case reports and series only.

\section{The Case}

A 15-month old child was brought to the clinic with failure to thrive, loss of weight and increasing head size for the past 8 months. There was no history of fever, vomiting, seizure or other significant antenatal history. He was delivered at full term, vaginal, without complications in this hospital. There was no family history of neurofibromatosis. On examination the child was alert and crying with head circumference of 50 centimeters. The anterior fontanel was wide and tense with dilated scalp veins. (Figure 1) Gross emaciation was present with absence of subcutaneous fat. Computed Tomography (CT) revealed a large suprasellar mass extending to the third ventricle causing biventricular obstruction. The tumor was well capsulated with ring enhancement and central hypodense area on contrast scan. There was gross hydrocephalus and severe papilledema. Nystagmus was absent. Magnetic Resonance Imaging was not done because the parents could not afford to do it. The child underwent biventricular ventriculoperitoneal shunting without any complications. 
He was followed up again after two months and was found to have moderate increased appetite, weight gain and partial reduction in head circumference (Fig. 2). The CT showed normal placement of the biventricular shunts and with no change in the tumor characteristics (Fig. 3). Pterional craniotomy and gross microscopic excision of the tumor was done. Intraoperatively there was a thick vascular capsule with thick, vascular semisolid jelly like contents. There was no local infiltration and the tumor was dissected free from the optic nerve, third cranial nerve, fifth cranial nerve and the left internal carotid branches. Postoperatively he was well except for fever. He developed seizure on the second day which turned to status epilepticus which was controlled but he developed aspiration pneumonia and despite all efforts he expired. The histopathology revealed the tumor to be fibrillary type of meningioma (Fig. 4).

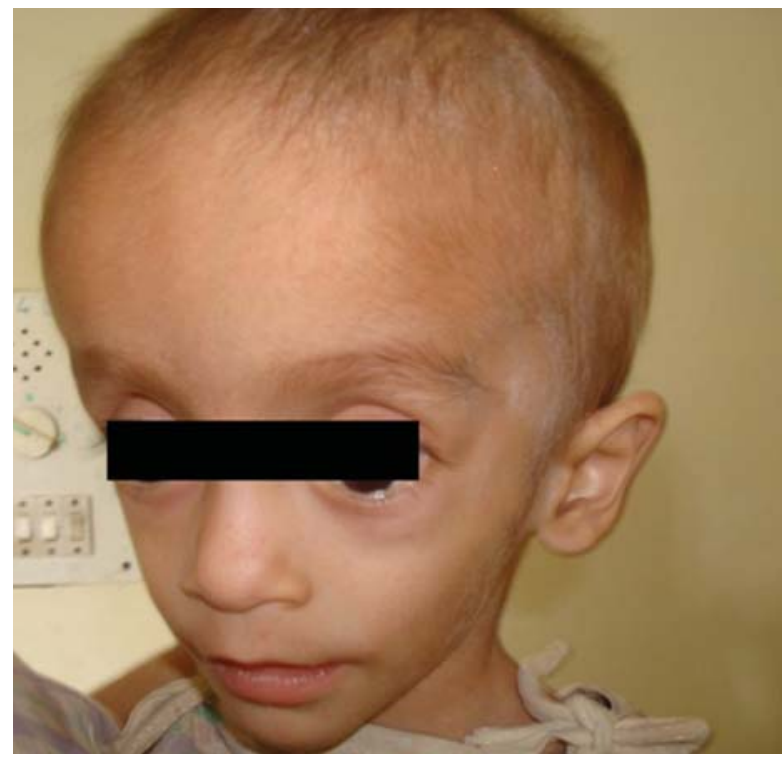

Fig. 1: Showing the enlarged head with dilated veins..

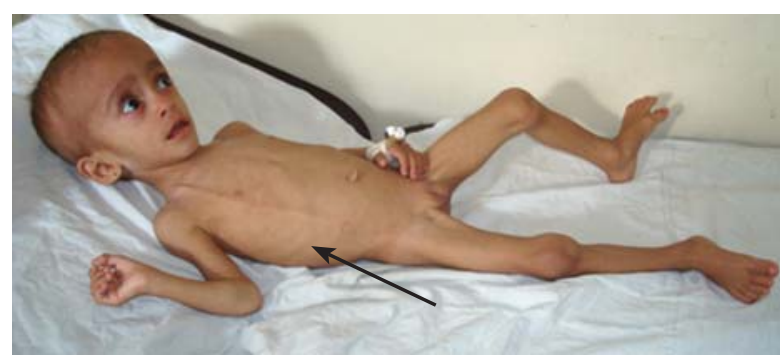

Fig. 2: Picture showing the child with emaciation, loss of subcutaneous fat and normal linear growth. The abdominal end of the VP shunt is also seen (arrow).

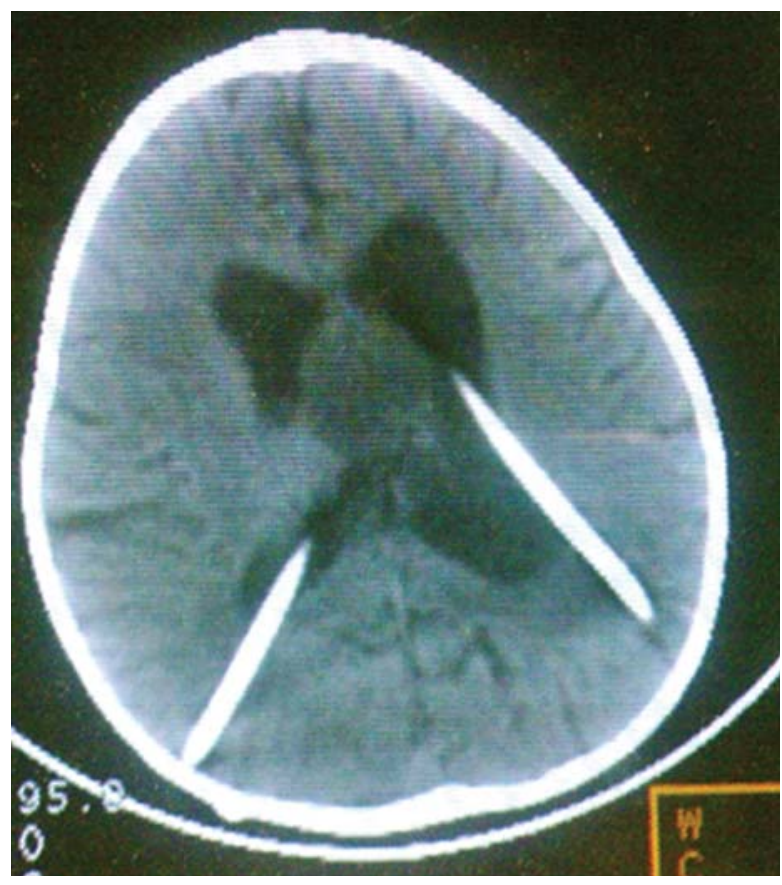

Fig. 3: CT showing the normal placement of biventricular shunt and the tumor in the third ventricle.

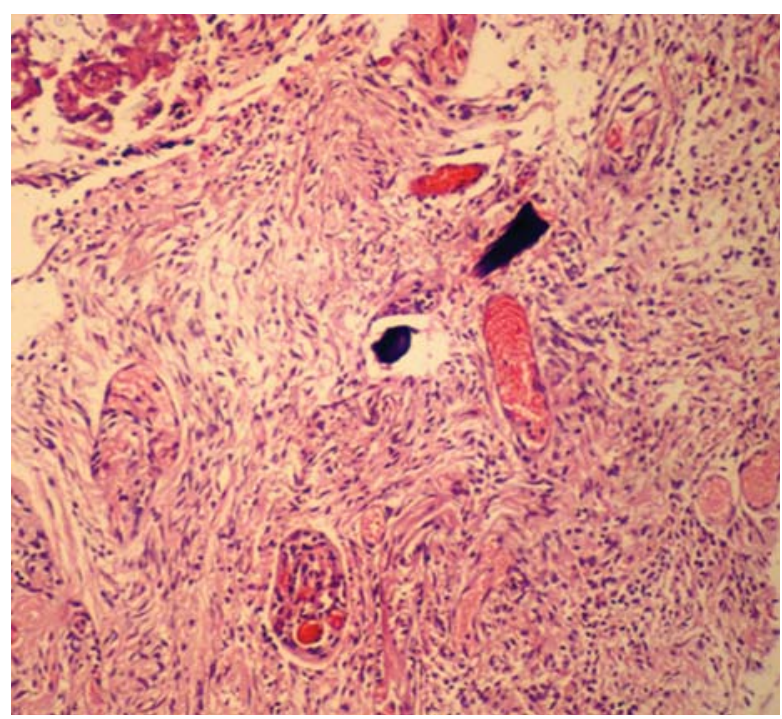

Fig. 4: Hematoxylin and Eosin stain photomicrograph showing dilated blood vessels, psammoma bodies (arrow) and fibrillary pattern of meningioma.

\section{Discussion}

Diencephalic syndrome is a rare cause for growth retardation in children who despite adequate intake are unable to grow normally. The common causes are tumors located in optico chiasmatic hypothalamic and the third ventricular areas ${ }^{4,5,6}$. The tumors associated with DS range from low grade pilocytic astrocytoma to malignant differentiated 
astrocytomas. The differentials include glioma (majority of which are astrocytomas), ependymoma, dysgerminoma, ganglioglioma and other rare tumors like spongioblastomas, astroblastomas, oligodendrogliomas, mixed astrocytoma/ spongioblastoma and mixed astrocytoma/ oligodendroglioma. DS has also been associated with lesions in the posterior fossa, and thalamic tumors ${ }^{6}$. Rare cases of its occurrence in adults secondary to third ventricular craniopharyngioma has also been reported?

These tumors usually manifest before the first year of life although delayed presentation have also been reported. In a series by Poussaint et al the mean age of presentation was 26 months ${ }^{6}$. The common clinical manifestation of DS are progressive emaciation, altered appearance, hyperactivity, vomiting, euphoria, pallor, nystagmus and hydrocephalus. The possible cause for failure to thrive is partial deafferentiation of the hypothalamic pathway by the tumor leading to altered feeding habits, increased metabolic rates and hormonal changes. Most of the studies have reported growth hormone resistance and other hormonal abnormalities ${ }^{8,9}$. The normal IGF-1 levels and consistent linear growth in DS suggest a more selective $\mathrm{GH}$-resistant state than in anorexia nervosa and other forms of emaciation. This finding also differentiates this diagnosis from that of other chronic illnesses or oncologic processes ${ }^{10}$.

Many of these tumors are unresectable due to their location and proximity to vital neurovascular structures. Some of them have been known to be multifocal in nature with even spinal dissemination ${ }^{11}$. This implies that a search be made for distal metastasis in all cases of tumors associated with DS and presenting with atypical symptoms. All cases with high grade glioma and residual tumor postoperatively need chemotherapy including carboplatin and vincristine which may lead to clinical improvement in these patients ${ }^{12}$. Radiotherapy has also been proven to be an useful adjunct although the probability of transformation into a higher grade though small is still present ${ }^{13}$.

Meningiomas are rare in children and representing $0.4-4.1 \%$ of pediatric tumors and $1.5-1.8 \%$ of all intracranial meningiomas ${ }^{14}$. Most of them are atypical and malignant in nature when compared with adult meningiomas. With complete excision the recurrence rate is low and the majority is associated with neurofibromatosis.

Although DS is uncommon it must be kept as a differential diagnosis in all children who fail to grow despite adequate intake. This is important in developing countries where the failure of growth is always attributed to malnutrition. In our case too the child would have passed as such if the there had been no enlargement of the head which led the parents for treatment. Early investigation, imaging and management can help to treat these children and assist them to lead a near normal life. Those with unresectable tumors need to undergo further chemotherapy or radiotherapy with long term followup.

\section{References}

1. Russell A. A Diencephalic Syndrome of Emaciation in Infancy and Childhood. Arch Dis Child. 1951; 26:274.

2. Addy DP, Hudson FP. Diencephalic Syndrome of Infantile Emaciation: Analysis of Literature and Report of further 3 Cases. Arch Dis Child. 1972; 47:338-343.

3. Burr IM, Slonim AE, Danish RK, Gadoth N, Butler IJ. Diencephalic Syndrome Revisited. J Pediatr. 1976; 88:439-44.

4. Huber J, Sovinz P, Lackner H, Mokry M, Eder H, Urban C. Diencephalic Syndrome: A Frequently Delayed Diagnosis in Failure to Thrive. Klin Padiatr 2007; 219:91-4.

5. Perilongo G, Carollo C, Salviati L, Murgia A, Pillon M, Basso G, et al. Diencephalic Syndrome and Disseminated Juvenile Pilocytic Astrocytomas of the Hypothalamic-Optic Chiasm region. Cancer. $1997 ; 1: 80: 142-6$

6. Poussaint TY, Barnes PD, Nichols K, Anthony DC, Cohen L, Tarbell NJ, et al. Diencephalic Syndrome: Clinical Features and Imaging Findings. Am J Neuroradiol 1997; 18:1499-505.

7. Miyoshi Y, Yunoki M, Yano A, Nishimoto K. Diencephalic Syndrome of Emaciation in an Adult associated with a Third Ventricle Intrinsic Craniopharyngioma: Case Report. Neurosurgery. 2003; 52:224-7.

8. Pimstone BL, Sobel J, Meyer E, Eale D. Secretion of Growth Hormone in the Diencephalic Syndrome of Childhood. J Pediatr. 1970; 76:886 -889.

9. Drop SLS, Guyda HJ, Colle E. Inappropriate Growth Hormone release in the Diencephalic Syndrome of Childhood: Case Report and 4 year Endocrinological follow-up. Clin Endocrinol. 1980; 13:181-187.

10. Fleischman A, Brue C, Poussaint TY, Kieran M, Pomeroy SL, Goumnerova L, Scott RM, Cohen 
LE. Diencephalic Syndrome: A Cause of Failure to Thrive and a Model of Partial Growth Hormone Resistance. Pediatr. 2005 115:742-8.

11. Perilongo G, Carollo C, Salviati L, Murgia A, Pillon M, Basso G, et al. Diencephalic Syndrome and Disseminated Juvenile Pilocytic Astrocytomas of the Hypothalamic-Optic Chiasm Region. Cancer. 1997 1; 80:142-6.

12. van der Wal EJ, Azzarelli B, Edwards-Brown M. Malignant Transformation of a Chiasmatic Pilocytic
Astrocytoma in a patient with Diencephalic Syndrome. Pediatr Radiol. 2003; 33:207-10.

13. Nomura $Y$, Yasumoto $S$, Yanai $F$, Akiyoshi $H$, Inoue $\mathrm{T}$, Nibu K, et al. Survival and Late effects on Development of Patients with Infantile Brain Tumor. Pediatr Int. 2008 Dec 29. [Epub ahead of print]

14. Tufan K, Dogulu F, Kurt G, Emmez H, Ceviker $\mathrm{N}$, Baykaner MK. Intracranial Meningiomas of Childhood and Adolescence. Pediatr Neurosurg. $2005 ; 41: 1-7$. 